RU Доля английского профессионального подъязыка в текстах учебных материалов для студентов строительных специальностей

\author{
Писарик О. И., Горожанов А. И.
}

\begin{abstract}
Аннотация. Настоящее прикладное исследование ставит перед собой цель установить долю участия подъязыка в наполнении текстов учебных материалов по английскому языку, применяемых в строительных вузах. Научная новизна заключается в том, что для определения актуальности содержания учебных материалов по критерию насыщенности элементами подъязыка специальности апробируется новый подход, который основывается на точных методах количественного и компаративного анализа с применением специализированного программного обеспечения. Полученные результаты показали, что доля элементов подъязыка специальности в анализируемых учебных материалах является недостаточно высокой. Обозначены пути улучшения их количественного и качественного наполнения.
\end{abstract}

\title{
EN Representation of the English-Language Professional Terminology in Educational Texts for Construction Specialities Students
}

\author{
Pisarik O. I., Gorozhanov A. I.
}

\begin{abstract}
This applied study aims to analyse representation of the English-language professional terminology in educational texts for construction specialities students. Scientific originality of the paper lies in the fact that terminological richness of educational texts is evaluated using digital data processing techniques. The conclusion is made about insufficient representation of professional terminology in the analysed texts. Ways to improve quantitative and qualitative content of educational materials are outlined.
\end{abstract}

\section{Введение}

Качественную профессиональную подготовку современного специалиста в области технических наук на сегодняшний день трудно представить без интеграции иностранного языка. Реформы в сфере высшего образования и ориентированность на вхождение в мировое образовательное пространство, а также стремительная информатизация образования предполагают пересмотр программ подготовки будущих специалистов в соответствии с тенденциями общественного развития и, как следствие, влекут за собой расширение спектра средств, необходимых для решения образовательных задач [25]. Профессионально ориентированный подход, согласно которому следует формировать у студентов компетенции, предусматривающие способность к иноязычному общению в конкретных ситуациях профессиональной коммуникации, а также умение работать с информацией по специальности из иноязычных аутентичных источников, требует отводить работе с элементами профессионального подъязыка при создании учебных материалов центральную роль. Иностранный язык как дисциплина основной образовательной программы уровня бакалавриата строительных направлений подготовки не может преподаваться качественно без включения в учебные материалы текстов, насыщенных современной профессиональной лексикой [16]. Необходимость учета указанных факторов, а также описания современного английского подъязыка строительства определяет актуальность настоящего исследования.

Материалом исследования являются актуальные учебные пособия по английскому языку как иностранному для студентов, обучающихся по направлению подготовки 08.03.01 Строительство, изданные не более трех лет назад, общим объемом около 950 страниц, а также аутентичные тексты пояснительных записок к зарубежным строительным проектам общим объемом 1017 страниц (исходя из этических принципов, наименования изучаемых изданий и документов не приводятся), которые можно считать «эталонными» для данной области. Анализ указанных материалов дает возможность выявить степень их насыщенности 
специальной лексикой - терминологией, которая является детерминирующей базой любого профессионального подъязыка [13, с. 29], а также определить долю соотношения употребления терминов в текстах учебных пособий и текстах пояснительных записок, включая частотность использования безличных предложений и конструкций со страдательным залогом.

Исследование предполагает решение следующих задач:

1. Провести количественный анализ аутентичных текстов пояснительных записок к зарубежным строительным проектам с целью установления доли элементов профессионального подъязыка.

2. Провести количественный анализ текстов учебных пособий по английскому языку с целью установления доли элементов профессионального подъязыка.

3. Провести компаративный анализ результатов, полученных в ходе решения первых двух задач, включая качественную оценку элементов подъязыка в учебных текстах на предмет их актуальности.

Соответственно, в качестве методов исследования были применены количественный и компаративный анализ текстов. Техническим инструментом для проведения анализа послужило специализированное программное обеспечение, разработанное в Лаборатории фундаментальных и прикладных проблем виртуального образования Московского государственного лингвистического университета [24].

В настоящее время проблеме выделения и описания такой языковой подсистемы, как языки профессиональной коммуникации, посвящено достаточно много научных работ, в которых внимание в основном сконцентрировано на общих механизмах появления, развития и обогащения подъязыков $[1 ; 2 ; 18 ; 19 ; 21]$. Также исследуется объем понятия «подъязык», определяется корреляция дефиниций «подъязык» и «язык для специальных целей» (англ. Language for Special/Specific Purposes), прослеживается путь становления подъязыка в канве общенационального языка $[5 ; 7 ; 10 ; 11 ; 20]$. Немалая доля исследований затрагивает область организации и реализации процесса преподавания иностранных подъязыков в контексте профессионально ориентированного обучения. Так, отечественные и зарубежные исследователи описывают различные технологии обучения иноязычной коммуникации студентов вузов на материале подъязыка как очно, так и в дистанционном формате $[4 ; 8 ; 9 ; 12 ; 14 ; 22 ; 23]$. Указанные работы послужили теоретической базой исследования.

Практическая значимость работы состоит в том, что ее результаты могут быть использованы для составления учебников и учебных пособий по английскому языку для студентов, обучающихся по направлению подготовки 08.03.01 Строительство.

\section{Анализ аутентичных текстов}

Чтобы решить первую задачу исследования, необходимо, прежде всего, уточнить, какие элементы подъязыка должны подлежать поиску. Для этого требуется разобраться в том, что представляет собой профессиональный подъязык.

Первые попытки создать учебные пособия для обучения профессиональным подъязыкам предпринял в 1925 г. Ч. К. Огден в рамках разработки Basic English. На базе общеупотребительного английского языка ученый создал его упрощенный вариант, содержащий словарь из 850 лексических единиц, который применялся в преподавании техническим специалистам [26]. Таким образом, благодаря проделанной Огденом работе был заложен фундамент для дальнейших исследований в этой области.

Стремительное развитие научно-технического прогресса в начале XX в. повлияло на все аспекты человеческой деятельности, в частности на формирование специфических подъязыковых систем профессиональной коммуникации. С середины XX в. статус языка международного профессионального общения приобретает английский язык благодаря значительному влиянию США на жизнь мировой общественности [15]. Следовательно, английский подъязык различных профессиональных областей стал играть доминирующую роль.

В конце 80-х гг. ХХ в. появление и активная разработка методики профессионально ориентированного обучения подтолкнули двух английских ученых Т. Хатчинсона и А. Уотерса к разработке «языка для специальных целей» [20]. В своих работах они сделали акцент на обучении специалистов различных технических областей английскому языку с учетом их профессиональных потребностей.

В отечественной предметно-специальной литературе понятие «подъязык» фиксируется с 1960-х гг. и определяется Н. Д. Андреевым как «более дробная единица, чем научный стиль» [2, с. 115]. По мнению исследователя, сформировалась некая подсистема, которая функционирует в ограниченных рамках профессионального общения и при этом основывается на ресурсах общенационального языка. При этом демаркирующей чертой данной подсистемы является пласт специальной лексики - терминология. Именно терминологический аппарат подъязыков профессиональных областей составляет наиболее активно развивающуюся и постоянно обновляющуюся основу их лексической базы [3].

Заметим, что термин «подъязык» не всегда связывается с профессиональной коммуникацией. Например, в трудах ученых Московской семантической школы мы находим следующие теоретические положения: «Ввиду национальной специфики языковой картины мира в качестве семантического метаязыка должен использоваться не универсальный искусственный язык, а подъязык изучаемого естественного языка... в подъязык отбираются относительно простые слова, грамматические формы слов и синтаксические конструкции в их основных значениях» [6, с. 11-13]. Таким образом, здесь подъязык представляет собой семантический метаязык, через который может быть описан естественный язык. 
Определение подъязыка, сформулированное Н. Д. Андреевым, поддерживается в работах А. В. Суперанской и Т. Н. Хомутовой. Исследователи определяют язык общего употребления как фон, источник, из которого подъязык черпает фонетическую, морфологическую и синтаксическую основу, а лексические особенности формируются под влиянием онтологических особенностей области употребления [18; 21]. Следует подчеркнуть и некоторые характерные особенности построения предложений, которые отличаются высоким процентом использования конструкций со сказуемым в страдательном залоге и безличных конструкций. Подобный синтаксис способствует сжатию объема и ускоренной передаче специального знания [17, с. 42].

Исходя из сказанного выше, при анализе аутентичных текстов пояснительных записок определим частотность использования терминов, а также сказуемых в форме страдательного залога и безличных предложений.

В результате количественного анализа текстов пояснительных записок к строительным проектам на английском языке были получены следующие результаты:

1) доля терминов составляет $42 \%$ от общего количества лексических единиц;

2) частотность употребления одних и тех же терминов в различных текстах пояснительных записок равна 64\%;

3) доля употребления конструкций со сказуемым в страдательном залоге по отношению к общему объему составляет $38 \%$.

Технически процесс анализа заключался в том, что оцифрованные текстовые материалы в формате ТХТ загружались в разработанную нами программу и далее путем автоматизированного отбора (то есть при участии человека и машины) токенизировались, другими словами, фрагменты, содержащие элементы профессионального подъязыка, отделялись от остального текстового массива с помощью набора регулярных выражений. Расчеты доли элементов подъязыка производились с помощью статистических функций указанной программы.

Из представленных выше данных следует, что доля подъязыка строительства в текстах пояснительных записок к проектам на английском языке значительна и составляет в общей сложности около половины всего текстового объема.

\section{Анализ учебных текстов}

После решения первой задачи исследования было выдвинуто предположение, что современные учебные и аутентичные тексты должны иметь сходную долю элементов подъязыка. Для подтверждения или опровержения этой гипотезы был проведен количественный анализ содержания текстов обозначенных выше учебных пособий с целью выявления процентного соотношения по тем же заданным параметрам, которые применялись и в отношении аутентичных текстов. Приведем результаты этого анализа:

1) доля насыщенности текстов учебных материалов терминами составляет $27 \%$ от общего количества лексических единиц;

2) частотность употребления одних и тех же терминов в различных текстах учебных пособий составляет $46 \%$;

3) доля употребления конструкций со сказуемым в страдательном залоге по отношению к общему объему равна $20 \%$.

Полученные данные указывают на значительное расхождение процентного содержания искомых элементов в учебных и аутентичных текстах.

\section{Компаративный анализ данных}

Компаративный анализ полученных данных показывает меньшие значения коэффициентов в учебных текстах по всем трем параметрам (см. Диаграмму 1).

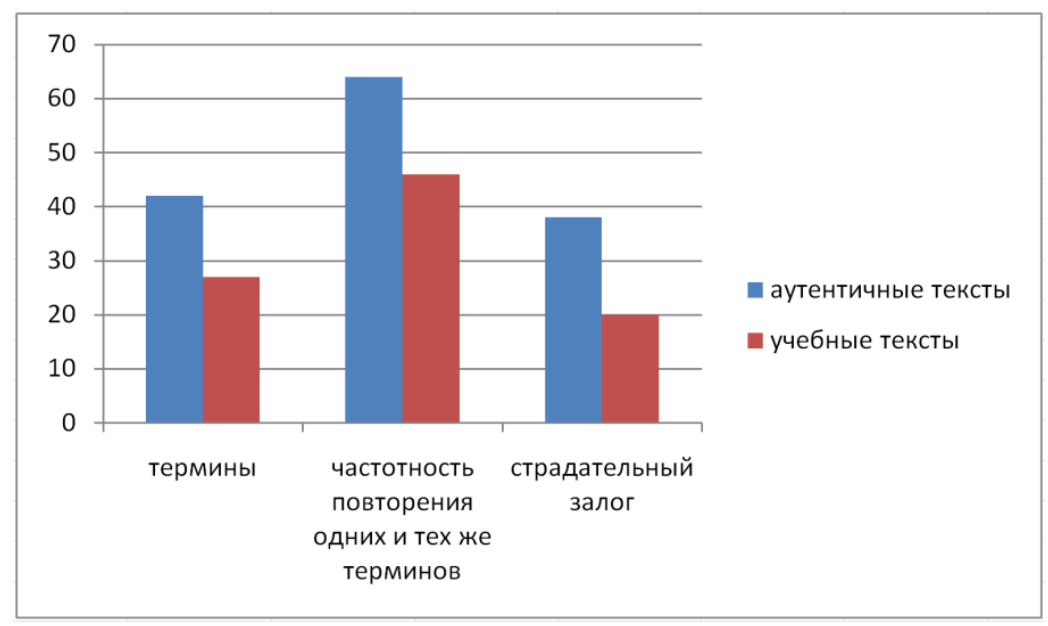

Диаграмма 1. Визуализация данных компаративного анализа 
Таким образом, в учебных текстах мы зафиксировали недостаточно высокую долю употребления терминов и демаркирующих синтаксических конструкций (например, типичных сочетаний с модальными глаголами: should be established, must comply, shall be applied). Кроме того, в учебных материалах обнаружено достаточно много неактуальной профессиональной лексики. Например, trade worker в значении «квалифицированный рабочий» следует заменить на tradesman; blueprint в значении «чертеж» должен быть замещен термином drawing; термин operation некорректно использовать в значении «эксплуатация здания или сооружения», так как актуальным является термин maintenance; объем понятия facility сегодня не включает в себя обозначение «здания или сооружения», следовательно, необходимо заменить его на термин building; понятия building design и structural engineering некорректно использовать как синонимы в значении «проектирование зданий и сооружений» - эти термины применяются для описания отличных друг от друга процессов проектирования: building design обозначает широкий спектр архитектурных, технических и инженерных процессов создания чертежей будущего здания, а structural engineering является научной дисциплиной, которая занимается анализом различных свойств конструкций на базе её компонентов.

На наш взгляд подобное расхождение содержания исследованных учебных материалов и содержания актуальных аутентичных текстов английского профессионального подъязыка вызвано в первую очередь отсутствием активного взаимодействия преподавателей и специалистов в области строительства, владеющих английским языком, поскольку основная цель обучения иноязычной коммуникации - дать представление о специальном языке общения, который поможет будущему специалисту без труда вербализировать знания и обмениваться ими с другими членами профессионального сообщества, а также сформировать навык его уместного и корректного употребления.

При подборе материалов для создания современных учебников и учебных пособий необходимо открыть доступ преподавателям к широкому спектру аутентичных текстов на иностранном языке, в частности на английском, которые имеют реальное применение в процессе профессионального общения. Это может стать возможным при условии реализации активного взаимодействия вуза и работодателя, например крупных строительных компаний и архитектурных бюро. Также представляется важным форсировать развитие сотрудничества профилирующих кафедр с кафедрами иностранных языков и профессиональной коммуникации внутри вуза с целью проведения большего количества мероприятий на английском языке для мотивации обучающихся и обучающих к углубленному изучению подъязыка профессиональной области.

\section{Заключение}

В ходе исследования мы пришли к следующим выводам.

1. В аутентичных текстах пояснительных записок к зарубежным строительным проектам доля терминов составляет $42 \%$ от общего количества лексических единиц, частотность употребления одних и тех же терминов в различных текстах равна $64 \%$, доля употребления конструкций со сказуемым в страдательном залоге по отношению к общему объему составляет $38 \%$.

2. В учебных текстах доля насыщенности текстов терминами составляет $27 \%$ от общего количества лексических единиц, частотность употребления одних и тех же терминов в различных текстах составляет 46\%, доля употребления конструкций со сказуемым в страдательном залоге по отношению к общему объему равна $20 \%$.

3. Компаративный анализ полученных данных показал более низкую долю элементов подъязыка и наличие значительного количества неактуальной лексики в учебных текстах.

В качестве перспектив исследования обозначим работу по составлению баз данных элементов подъязыка строительства на основе количественного и компаративного анализа аутентичных текстов этой области народного хозяйства с целью перманентной актуализации учебно-методических материалов по английскому языку для будущих строителей.

\section{Список источников}

1. Акимова О. В. Специализированные подъязыки и дискурс в аспектах перевода // Казанский лингвистический журнал. 2019. Вып. 1 (29). С. 21-31.

2. Андреев Н. Д. Статистико-комбинаторное моделирование языков. М.: Наука, 1965. 502 с.

3. Андреев Н. Д. Статистико-комбинаторные методы в теоретическом и прикладном языковедении. Л.: Наука, 1967. 403 с.

4. Андреева М. И., Солнышкина М. И. Семантические модели единиц, номинирующих эмоции в английских профессиональных подъязыках // Вестник Марийского государственного университета. 2017. Вып. 3 (27). С. 87-92.

5. Анненкова А. В. Понятие языка профессионального общения // Язык для специальных целей: система, функции, среда: сб. статей IV Междунар. науч.-практ. конф. Курск: ЮЗГУ, 2012. С. 12-15.

6. Апресян Ю. Д. О Московской семантической школе // Вопросы языкознания. 2005. № 1. С. 3-30.

7. Герд А. С. Введение в изучение языков для специальных целей: учеб. пособие. Изд-е 2-е, доп. и перераб. СПб.: СПбГУ, 2011. 60 с.

8. Горожанов А. И. Программные решения оптимизации процессов управления и составления электронных учебных материалов в LMS Moodle // Вестник Московского государственного лингвистического университета. 2020. Вып. 7 (836). С. 33-43. 
9. Горожанов А. И. Формирование обучающей виртуальной среды в контексте новых информационных технологий: дисс. .... д. филол. н. М.: МГЛУ, 2018. 535 с.

10. Зяблова О. А. Принципы исследования языка для специальных целей: на примере языка экономики: дисс. ... д. филол. н. М.: Ин-т языкознания РАН, 2005. 316 с.

11. Конурбаев М. Э., Забросаева И. А. От LSP до специализированного дискурса: исторический срез // Язык, сознание, коммуникация. 2014. Вып. 49. С. 26-87.

12. Корниенко О. П. Терминологическая специфика английских текстов подъязыка архитектуры и строительства // Известия Российского государственного педагогического университета им. А. И. Герцена. 2008. Вып. 63. С. 151-155.

13. Лейчик В. М. Языки для специальных целей - функциональные разновидности современных развитых функциональных языков // Общие и частные проблемы функциональных стилей: сб. статей / отв. ред. М. Я. Цвиллинг. М.: Наука, 1986. С. 28-43.

14. Макар Л. В. Обучение профессионально-ориентированному общению на английском языке студентов неязыкового вуза: дисс. ... к. пед. н. СПб.: Российский гос. пед. ун-т им. А. И. Герцена, 2000. 257 с.

15. Миньяр-Белоручева А. П. История становления языка для специальных целей // Актуальные проблемы теоретической и прикладной лингвистики: материалы Междунар. науч. конф.: в 2-х ч. Челябинск: Изд-во ЮУрГУ, 2007. Ч. 1. С. 24-30.

16. Об утверждении Федерального государственного образовательного стандарта высшего образования - бакалавриат по направлению подготовки 08.03.01 Строительство [Электронный ресурс]: Приказ Министерства образования и науки Российской Федерации от 31.05.2017 № 481. URL: https://www.garant.ru/products/ ipo/prime/doc/71605256/ (дата обращения: 06.02.2021).

17. Раздуев А. В. Современный английский подъязык нанотехнологий: структурно-семантическая, когнитивно-фреймовая и лексикографическая модели: дисс. ... к. филол. н. Пятигорск: ПГлУ, 2013. 241 с.

18. Суперанская А. В. Общая терминология. Вопросы теории. М.: Наука, 2003. 246 с.

19. Фельде О. В. Языки для специальных целей в историко-лингвистическом аспекте // Вестник Бурятского государственного университета. 2013. Вып. 10. С. 50-56.

20. Хасанова 3. Х. Подъязык и его функционально-системные характеристики // Lingua Mobilis. 2013. Вып. 1 (40). C. 64-79.

21. Хомутова Т. Н. Язык для специальных целей (LSP): лингвистический аспект // Известия Российского государственного педагогического университета им. А. И. Герцена. 2008. Вып. 71. С. 96-106.

22. EL-Sakran T. Peer and self-assessment in a professional communication course: Does task type make a difference? // Journal of Languages for Specific Purposes (JLSP). 2020. № 7. P. 24-41.

23. Fogarasi K., Kránicz R., Halász R., Hambuch A. Die Rolle medizinischer Wissensvermittlung in Arzt-PatientenGesprächen: die Bedeutung des ärztlichen Code-Wechsels in hausärztlichen Konsultationen // Journal of Languages for Specific Purposes (JLSP). 2020. № 7. P. 83-96.

24. Gorozhanov A. I., Guseynova I. A. Corpus analysis of the grammatical categories' constituents in fiction texts considering the linguo-regional component // Journal of Siberian Federal University. Humanities \& Social Sciences. 2020. Vol. 13. № 12. P. 2035-2048. DOI: 10.17516/1997-1370-0702.

25. Guseynova I. A., Gorozhanov A. I., Kosichenko E. F. Development of linguistic institutional educational virtual environment at Moscow State Linguistic University (2016-2018) // SHS Web Conference. The International Scientific and Practical Conference 'Current Issues of Linguistics and Didactics: The Interdisciplinary Approach in Humanities and Social Sciences’ (CILDIAH-2019). 2019. Vol. 69. P. 1-7. DOI: 10.1051/shsconf/20196900045.

26. Ogden Ch. K. Basic English: A General Introduction with Rules and Grammar. L.: Paul Treber \& Co., Ltd., 1930. 489 p.

\section{Информация об авторах | Author information}

RU Писарик Оксана Ивановна ${ }^{1}$

Горожанов Алексей Иванович ${ }^{2}$, д. филол. н., доц.

1,2 Московский государственный лингвистический университет

EN Pisarik Oksana Ivanovna ${ }^{1}$

Gorozhanov Alexey Ivanovich ${ }^{2}$, Dr

${ }^{1,2}$ Moscow State Linguistic University

${ }^{1}$ ksyfrolova93@gmail.com, ${ }^{2}$ a_gorozhanov@mail.ru

\section{Информация о статье | About this article}

Дата поступления рукописи (received): 08.02.2021; опубликовано (published): 09.04.2021.

Ключевые слова (keywords): подъязык; строительная терминология; количественный анализ; компаративный анализ; английский язык; sublanguage; construction terminology; quantitative analysis; comparative analysis; English language. 